промышленного предприятия задачи точного позиционирования пневматического исполнительного механизма, используя контроллер с программой, реализующей ПИД-импульсный алгоритм, 5/3-распределитель со средним отсечным положением предоставленными компанией CAMOZZI.

Принципиально важным в процессе обучения студентов считаем не «голый» процесс передачи знаний, которые студент зачастую даже не понимает для чего они ему нужны, а непосредственную работу со студентом над конкретной прикладной задачей, в процессе работы на которой студент сам сталкивается с проблемами, формулирует задачи и самостоятельно подходит к недостатку знаний в определенном направлении. Мотивированный таким образом молодой человек будет самостоятельно разбираться, а преподаватель при этом становится просто консультантом, который деликатно напрвляет, подсказывает и помгает юнному специалисту в освоении дисциплины.

Выводы

В контексте нашей научно - исследовательской лаборатории «Мехатроники и робототехники» высказывание знаменитого древнегреческого философа Плутарха из Херонеи «Ученик — это не сосуд, который надо наполнить, а факел, который надо зажечь» приобрело у нас новое прочтение - мы не просто «зажигаем» наших студентов на увлекательнейшую научную работу, мы «горим» вместе с ними.

\title{
ИСПОЛЬЗОВАНИЕ НЕЙРОННЫХ СЕТЕЙ КАК ФАКТОРА ПОВЫШЕНИЯ КАЧЕСТВА И БЕЗОПАСНОСТИ ПРОИЗВОДСТВА ПИЩЕВЫХ ПРОДУКТОВ ПРИ РЕШЕНИИ ЗАДАЧ АВТОМАТИЗАЦИИ
}

\author{
Еделев Д.А. ${ }^{1}$, Благовещенская М.М. ${ }^{1}$, Благовещенский И.Г. ${ }^{1}$ \\ ${ }^{1}$ ФГБОУ ВПО «Московский государственный университет пищевых производств», Москва
}

Copyright (C) 2014 by author and the journal “Automation technological and business - processes". This work is licensed under the Creative Commons Attribution International License (CC BY). http://creativecommons.org/licenses/by/4.0/

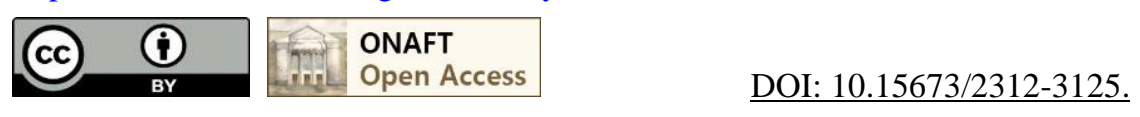

\begin{abstract}
Аннотация
В настоящее время пищевая промышленность вступила в период бурного развития. Конкуренция на данном рынке резко возросла. Для каждого отдельного предприятия остро стоит проблема производства высококачественного отечественного продукта с длительными сроками хранения без добавок консервантов. Решение этой проблемы тесно связано с широкой автоматизацией технологических процессов, внедрением новых информационных технологий, появлением необходимых средств контроля для реализации автоматизированных систем управления, проведением организационно-технических мероприятий, способствующих улучшению качества, повышению безопасности и увеличению ассортимента выпускаемых пищевых продуктов.
\end{abstract}


Abstract

Now the food industry entered the period of rapid development. The competition in this market sharply increased. For each separate enterprise the problem of production of a high-quality domestic product with long periods of storage without additives of preservatives is particularly acute. The solution of this problem is closely connected with broad automation of technological processes, introduction of new information technologies, emergence of necessary control devices for realization of automated control systems, carrying out the organizational and technical actions promoting quality improvement, increase of safety and increase in the range of the let-out foodstuff.

Ключевые слова

Пищевая промышленность, автоматизация технологических процессов, информационные технологии.

В настоящее время пищевая промышленность вступила в период бурного развития. Конкуренция на данном рынке резко возросла. Для каждого отдельного предприятия остро стоит проблема производства высококачественного отечественного продукта с длительными сроками хранения без добавок консервантов. Решение этой проблемы тесно связано с широкой автоматизацией технологических процессов, внедрением новых информационных технологий, появлением необходимых средств контроля для реализации автоматизированных систем управления, проведением организационно-технических мероприятий, способствующих улучшению качества, повышению безопасности и увеличению ассортимента выпускаемых пищевых продуктов.

Проведенный нами обзор и анализ литературы [1- 6] показал, что в настоящее время пищевые предприятия являются сложными технологически ёмкими структурами. Процесс производства пищевых продуктов состоит из множества отдельных подпроцессов, в которых участвуют самостоятельные виды оборудования по очистке и хранению сырья; сепарированию, темперированию, размолу, формованию пищевых масс и т.д. [1, 2]. Применение в единой технологической цепочке большого количества оригинального технологического оборудования, имеющего персональные входные характеристики сырья и выходные - продукции, усложняют процедуру автоматизации контроля параметров, характеризующих эффективность проводимых этапов производства, работы оборудования, а также качество получаемой готовой продукции.

Существующие в настоящее время методы оценки качества пищевых продуктов, в основном, субъективны, определяются зачастую путем лабораторных измерений, ввиду невозможности технического решения по организации их измерения поточным способом [3]. Так, в настоящее время основным заключающим фактором об органолептических показателях качества готовых пищевых масс является оценка экспертов [5]. При выполнении всех требований и рекомендаций в оценке качества такая оценка может давать недостоверные и необъективные показания о качестве готовой продукции. На основании опыта выявлено, что обычно не более $40 \%$ испытуемых экспертов выдерживают тесты на чувствительность органов обоняния и вкуса, однако этот фактор очень важен для получения надежных, достоверных и сопоставимых результатов.

Ситуация в отраслях пищевой промышленности России требует новых подходов к решению этой важной проблемы и поиску альтернативных вариантов развития автоматизации контроля. Одно из основных направлений развития пищевой промышленности связано с автоматизацией контроля показателей качества сырья, полуфабрикатов и готовых изделий, включая и органолептические показатели. Назрела необходимость повышения объективности контроля качества пищевых продуктов за счет внедрения высокоэффективных интеллектуальных технологий в производственный процесс и создания на их базе интелектуальной автоматизированной системы контроля.

Автоматизация контроля показателей качества пищевых масс в процессе из приготовления с использованием интеллектуальных технологий и сведение их результатов в единый программно- аппаратный комплекс (ПАК) для создания автоматизированной системы управления технологическими процессами (АСУТП) жизненно необходима. Создание ПАК позволит: непрерывно, в потоке контролировать показатели качества перерабатываемого сырья, полуфабрикатов и определять оптимальный режим протекания технологического процесса (ТП); обеспечить стабильность производства пищевых изделий; соблюдение установленных технологических режимов; повысить надёжность работы оборудования, а также будет способствовать стабилизации качества готовой продукции; снижению издержек при эксплуатации, уменьшит влияние человеческого фактора на объективность анализа, сократит производственный цикл выпуска пищевых изделий, исключив стадию органолептической оценки качества готового продукта.

Успешное решение этой задачи при минимальных затратах на подготовку и проведение анализов становится возможным, благодаря внедрению в производственные процессы кондитерского, мукомольного, хлебопекарного и пивобезалкогольного производства разработанного нами автоматизированного программно-аппаратного 
комплекса (ПАК) контроля основных показателей качества пищевых продуктов, в основе алгоритма работы которого заложена нейросетевая модель (НСМ). Функционирование НСМ базируется на применении аппарата искусственных нейронных сетей (НС), который является одним из направлений развития теории искусственного интеллекта.

Модель НС состоит из одного или нескольких слоев искусственных нейронов, которые имитируют работу своих биологических аналогов (нервных клеток). Базовыми элементами автоматизированного ПАК являются [4]:

- микропроцессорные устройства сбора, обработки и передачи информации (входят в состав автоматизированной системы управления технологическим процессом (АСУ ТП));

- человеко-машинный интерфейс, позволяющий осуществлять обмен данными между оператором и микропроцессорным устройством;

- система управления базами данных (СУБД);

- программное обеспечение, в основе алгоритма которого заложена НСМ;

- шлюзовое программное обеспечение (позволяет осуществлять сбор, преобразование и передачу данных между различными коммуникационными протоколами).

На сегодняшний день аппараты искусственных НС и методы их применения активно развиваются и совершенствуются. Активными исследованиями в области создания систем моделирования искусственных нейронных сетей (ИНС) в России занимаются такие организации как Институт вычислительного моделирования CO РАН, ФГБОУ ВПО «Исследовательский ядерный университет «МИФИ»», Пермская научная школа искусственного интеллекта, ЗАО "Научно-исследовательский центр математического моделирования и нейросетевых технологий "Нейросплав". Исследования в этой области проводили Д. Рутковская, М. Пилиньский, Л. Рутковский, А. И. Галушкин, Саймон Хайкин, А. Б. Барский, А. А. Ежов, С. А. Шумский, А. Н. Горбань, M.M. Благовещенская. Вместе с тем опубликованы ряд диссертационных работ, посвященных вопросам использования ИНС в различных областях, в том числе и в пищевой промышленности: «Математическое и алгоритмическое обеспечение задачи автоматизации процесса дезинфекции ПЭТ-бутылок с помощью озона» (к.т.н. Роденков Е.В., научный руководитель д.т.н., проф. Благовещенская М.М. 2005), «Автоматизация контроля показателей вкуса шоколадных изделий» (к.т.н. Шаверин А. В., научный руководитель д.т.н., проф. Благовещенская М.M. 2009), «Автоматизация контроля влажности кондитерских масс с применением интеллектуальных технологий» (к.т.н. Апанасенко С. И., научный руководитель д.т.н., проф. Благовещенская M.M. 2010), «Разработка научных принципов проектирования состава и совершенствования технологии многокомпонентных мясных изделий с использованием вторичных ресурсов пищевой промышленности» (д.т.н. Садовой В. В., 2007), «Сенсорометрический метод в оценке качества пищевых жиров и масел» (к.Х.н. Селиванова А. А., 2011) [1 - 6] и др.

Еще одним перспективным направлением автоматизации ТП пищевых производств является использование системы технического зрения в качестве интеллектуального датчика в системах автоматического регулирования технологическими процессами. К настоящему времени опубликованы ряд диссертационных работ, посвященных вопросам использования цифровой видеосъемки в различных областях, в том числе и в пищевой промышленности: «Система автоматического регулирования процесса формования конфетных жгутов с использованием цифровой видеосъемки» (к.т.н. Иванов Я. В., научный руководитель д.т.н., проф. Благовещенская М.М. 2008), «Автоматизация контроля цветовых показателей качества хлебобулочных изделий с применением спектральной квалиметрии» (к.т.н. Ребриков Д.И., научный руководитель д.т.н., проф. Битюков В.К. 2010), «Совершенствование технологии хлеба для школьного питания с применением автоматизированной системы контроля цвета изделия» (к.т.н. Шторх Л.В., научный руководитель д.т.н., проф. Чертов Е.Д. 2013) и др.

Выводы: Анализ опубликованных научных работ в области искусственных нейронных сетей (ИНС) и системы технического зрения (СТЗ) свидетельствует о перспективности исследований по этой тематике, необходимости развития этого научного направления, а так же малочисленности данных исследований в области пищевой промышленности. Изучение отечественной и зарубежной литературы указывает на необходимость углубленного исследования в рассматриваемых областях, применения новых подходов к использованию ИНС и системы технического зрения для построения интеллектуальных датчиков с учетом специфики каждой отрасли пищевой промышленности; исследование возможности интеграции таких датчиков в систему управления технологическими процессами производства пищевых продуктов. 
Литература

1. Благовещенская, М.М. Информационные технологии систем управления технологическими процессами. Учеб. для вузов/ М.М. Благовещенская, Л.А. Злобин. // - М.: Высш. шк., 2005.- 768 с;

2. Благовещенская М.М. Основы стабилизации процессов приготовления многокомпонентных пищевых масс. Монография // - М.:ООО «Франтера», 2009. - 281 с;

3. Шаверин А.В., Благовещенская М.М., Благовещенский И.Г. Создание программно-аппаратного комплекса для оценки показателей вкуса кондитерских изделий // Сб. докладов II Конференции молодых ученых «Реология и физико-химическая механика гетерофазных систем», Звенигород, 2009. - с.58 - 60;

4. Шаверин А.В., Благовещенская М.М., Благовещенский И.Г. Автоматизированная система интеллектуального контроля вкуса шоколадных изделий // «Хранение и переработка сельхозсырья» №11, «Пищевая промышленность», 2009 - с.67 - 68;

5. Благовещенская М.М., Роденков Е.В., Крылова Л.А., Благовещенский И.Г. Использование нейронных сетей как фактора повышения качества и безопасности пивобезалкогольных напитков при дезинфекции ПЭТ-бутылок. «Хранение и переработка сельхозсырья», №7, 2013. - с.24;

6. Благовещенская М.М., Иванов Я.В., Благовещенский И.Г., Крылова Л.А. Система автоматического регулирования процесса формирования конфетных жгутов. Пищевая пром-ть», №5, - 2013. - с.46 - 49.

References

1. Blahoveshchenskaya, M.M. Ynformatsyonnye tekhnolohyy system upravlenyya tekhnolohycheskymy protsessamy. Ucheb. dlya vuzov/ M.M. Blahoveshchenskaya, L.A. Zlobyn. // - M.: Vyssh. shk., 2005.- 768 s;

2. Blahoveshchenskaya M.M. Osnovy stabylyzatsyy protsessov pryhotovlenyya mnohokomponentnykh pyshchevykh mass. Monohrafyya // - M.:OOO «Frantera», 2009. - $281 \mathrm{~s}$;

3. Shaveryn A.V., Blahoveshchenskaya M.M., Blahoveshchenskyy Y.H. Sozdanye prohrammno-apparatnoho kompleksa dlya otsenky pokazateley vkusa kondyterskykh yzdelyy // Sb. dokladov II Konferentsyy molodykh uchenykh «Reolohyya y fyzyko-khymycheskaya mekhanyka heterofaznykh system», Zvenyhorod, 2009. - s.58 60 ;

4. Shaveryn A.V., Blahoveshchenskaya M.M., Blahoveshchenskyy Y.H. Avtomatyzyrovannaya systema yntellektual'noho kontrolya vkusa shokoladnykh yzdelyy // «Khranenye y pererabotka sel'khozsyr'ya» \#11, «Pyshchevaya promyshlennost'», 2009 - s.67 - 68;

5. Blahoveshchenskaya M.M., Rodenkov E.V., Krylova L.A., Blahoveshchenskyy Y.H. Yspol'zovanye neyronnykh setey kak faktora povyshenyya kachestva y bezopasnosty pyvobezalkohol'nykh napytkov pry dezynfektsyy PЭTbutylok. «Khranenye y pererabotka sel'khozsyr'ya», \#7, 2013. - s.24;

6. Blahoveshchenskaya M.M., Yvanov Ya.V., Blahoveshchenskyy Y.H., Krylova L.A. Systema avtomatycheskoho rehulyrovanyya protsessa formyrovanyya konfetnykh zhhutov. «Pyshchevaya prom'», \#5, -2013. - s.46 - 49.

\section{Е НОВОСТИ АВТОМАТИЗАЦИИ}

\section{Начата работа по созданию саморазвивающегося программного обеспечения способного поддерживать себя в актуальном состоянии сотни лет.}

Одна из проблем современности заключается в том, что используемое программное обеспечение достаточно быстро и с угнетающей регулярностью становится устаревшим, его функциональность перестает соответствовать уровню развития аппаратных средств вычислительных систем и все возрастающим потребностям его пользователей. И если большинство простых пользователей еще может как-то смирится с использованием устаревшего программного обеспечения, то для больших организаций и государственных структур, таких, как вооруженные силы, это является достаточно серьезной проблемой. Принимая это во внимание, Управление перспективных исследовательских программ Пентагона DARPA начало выполнение новой программы BRASS (Building Resource Adaptive Software Systems), целью которой является создание систем программного обеспечения, способных постоянно саморазвиваться, поддерживая свою функциональность в актуальном состоянии в течение минимум ста лет.

(http://www.dailytechinfo.org/) 